\title{
CARACTERIZAÇÃO QUÍMICA SUBSUPERFICIAL DO SOLO DO CEMITÉRIO MUNICIPAL SÃO SEBASTIÃO EM JOÃO PESSOA - PB
}

Paula Rose de Araújo Santos ${ }^{1}$, Antonio Faustino de Almeida Neto ${ }^{2}$ Rebeca Tibau Aguiar $^{3}$, Williams da Silva Guimarães de Lima ${ }^{4}$, Marco Aurélio Rodrigues de Melo ${ }^{5}$

1E-mail: Paulajp-rose@hotmail.com, Engenheira Ambiental pela Faculdade Internacional da Paraíba. João Pessoa. Brasil.

${ }^{2}$ Graduando em Engenharia Ambiental pela Faculdade Internacional da Paraíba. João Pessoa. Brasil

${ }^{3}$ Doutorando do Programa de Pós-Graduação em Ciências e Engenharia de Materiais. João Pessoa. Brasil

${ }^{4}$ Geógrafo. Presidente do Grupo Amigos da Barreira - GAB. João Pessoa. Brasil.

${ }^{5}$ Doutor em Química pela Universidade Federal da Paraíba. João Pessoa. Brasil

Recebido em: 22/09/2018 - Aprovado em: 23/11/2018 - Publicado em: 03/12/2018

DOI: 10.18677/EnciBio_2018B127

\begin{abstract}
RESUMO
Levando em consideração que os cemitérios são fontes potenciais de contaminação, há a preocupação com as consequências que a atividade cemiterial possa causar a região circunvizinha. $O$ referido trabalho teve por objetivo analisar quimicamente o solo subsuperficial e inferir sobre os impactos ambientais de alguns elementos do Cemitério Municipal São Sebastião, no município de João Pessoa, PB. Sendo assim, foram realizadas coletas em oito pontos a $0,5 \mathrm{~m}$ de profundidade com auxílio de um trado manual. As análises químicas avaliadas foram de alumínio, cálcio, magnésio, matéria orgânica, carbonato e bicarbonato por titulometria; potássio e sódio por espectrofotometria de chamas; nitrogênio pelo método de Kjeldahl por destilação a vapor e $\mathrm{pH}$. Os resultados demonstraram o elevado índice de alumínio, cálcio e magnésio, assim como a acidez no solo. Os elevados níveis de alumínio podem ter relação com os empreendimentos que estão localizados próximo ao cemitério, posto de gasolina, oficina mecânica e lava-jato, e no período de chuvas podem estar carreando esses materiais para dentro do cemitério.
\end{abstract}

PALAVRAS-CHAVE: Contaminação; solo; cemitério.

\section{CHEMICAL CHARACTERIZATION OF THE SUPSURFACE SOIL OF THE SÃO SEBASTIÃO MUNICIPAL CEMETERY IN JOÃO PESSOA - PB}

\begin{abstract}
Considering that the cemeteries are potential sources of contamination, there is concern for the consequences that cemeterial activity may cause to the surrounding region. This work aimed to carry out chemical analysis of topsoil and infer about the environmental impact of some chemical elements of the San Sebastian's Municipal Cemetery, in the city of João Pessoa, PB. Therefore, samples were taken in eight points to $0.5 \mathrm{~m}$ deep with help of a manual auger. The chemical analyzes were performed to quantify aluminum, calcium, magnesium, organic matter, carbonate,
\end{abstract}


and bicarbonate by titration; potassium and sodium by flame spectrophotometry; nitrogen by Kjeldahl steam distillation and $\mathrm{pH}$. The results demonstrated high aluminum, calcium and magnesium contents, as well as soil acidity. Elevated levels of aluminum may be related to developments that are located near the cemetery, gas station, auto repair shop, and jet launderers, and in the rainy season may be driving these materials into the graveyard.

KEYWORDS: Contamination, soil, cemetery.

\section{INTRODUÇÃO}

O solo apresenta boa capacidade de degradação vegetal e animal. O homem o utiliza por um longo tempo como depósito para enterrar seus mortos. Essa prática pode ocasionar sérios problemas ao meio ambiente e à saúde da população (PAÍGA; DELERUE-MATOS, 2016).

No passado, os cemitérios eram construídos distantes de povoamentos. Com o crescimento da população, eles passaram a fazer parte do interior das cidades. Desta foram estão instalados muitas vezes sem o devido planejamento, principalmente das necrópoles que se tornaram potenciais riscos de contaminação para a população local e para o meio ambiente (BENNETT; DAVIES, 2015; PAÍGA; DELERUE-MATOS, 2016; SWENSEN, 2018). Portanto, é de grande importância que o local de instalação de um cemitério seja previamente investigado para evitar consequências negativas à população (PAÍGA; DELERUE-MATOS, 2016).

A maneira de realizar o sepultamento contribui para a contaminação do solo que pode ocorrer por inumação ou tumulação. O primeiro consiste em enterrar o corpo diretamente no solo e o outro, em urnas. Em ambos casos, há contato da água da chuva ou de subterrâneos com o cadáver, lixiviando contaminantes orgânicos ou metálicos para o solo ou lençol freático (SANTOS, 2013).

Além disso, há mudanças na decomposição do corpo em função da temperatura, umidade e tipo de solo. A saponificação ou adipocere promove um aspecto de cera no cadáver quando o ambiente é úmido (RATTENBURRY, 2017). O contrário, a mumificação acontece quando o solo é seco, árido e quente (RATTENBURRY, 2017). De acordo com Cockle e Bell (2017), a mumificação é o processo pelo qual a umidade do tecido é perdida devido à evaporação.

Os cemitérios são propícios a causar sérios impactos negativos não só a sociedade, mas também ao meio ambiente (PAÍGA; DELERUE-MATOS, 2016). Com isso, precisam ser devidamente instalados e gerenciados de forma correta. No Brasil, o Conselho Nacional do Meio Ambiente (CONAMA) nํ 335/2003 trata do licenciamento ambiental dos cemitérios (BRASIL, 2003) e 0 art. 1ํ da Resolução CONAMA 420/2009 dispõe sobre critérios e valores orientadores de qualidade do solo quanto à presença de substâncias químicas e estabelece diretrizes para o gerenciamento ambiental de áreas contaminadas por essas substâncias em decorrência de atividades antrópicas (BRASIL, 2009).

Os estudos referentes a essa temática são escassos, mas de grande importância para compreender que os cemitérios trazem riscos potenciais à saúde da população em torno destes locais (PAÍGA; DELERUE-MATOS, 2016). Estudos realizados no Brasil atestam os diversos potenciais de contaminação cemiterial (ZYCHOWSKI; BRYNDAL, 2015). Tendo em vista que os cemitérios causam grande contaminação às pessoas, esse trabalho tem como objetivo realizar análises químicas do solo subsuperficial e inferir sobre seus impactos ambientais. 


\title{
MATERIAL E METÓDOS
}

Caracterização da Área de Estudo

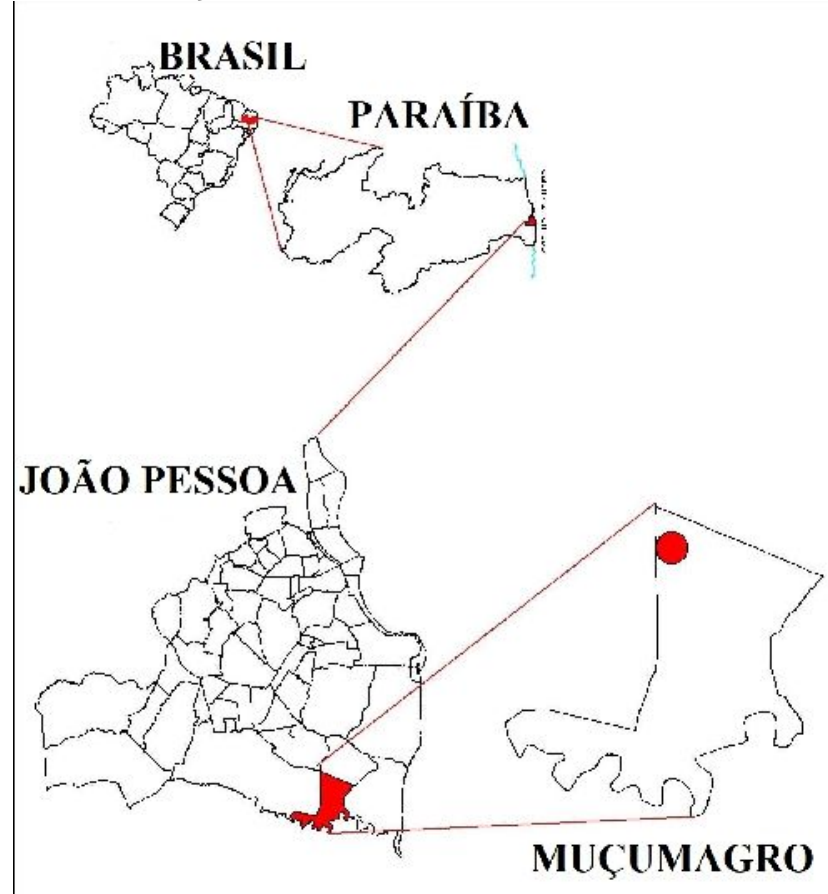

\author{
CEMITÉRIO SÃo SEBASTIÃo
}

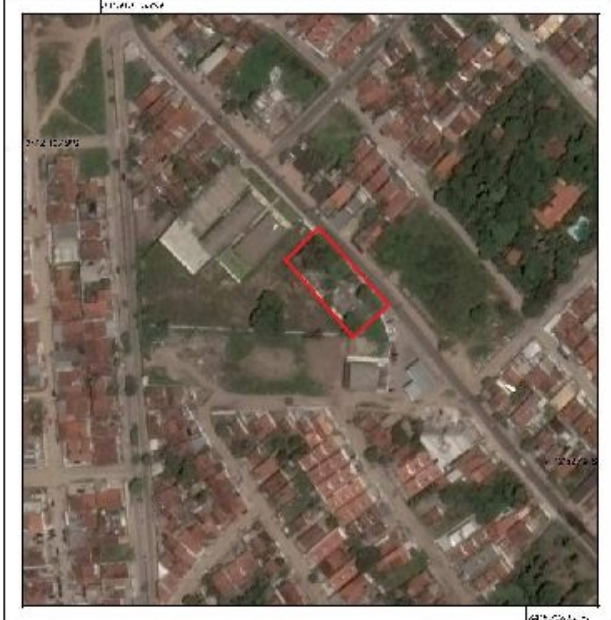

FIGURA 1 - Localização do Cemitério São Sebastião. Fonte: Autores.

O cemitério São Sebastião está localizado no litoral paraibano, no município de João Pessoa- PB, limitando-se ao norte com a cidade Cabedelo, ao sul com Conde, a oeste com os municípios de Bayeux e Santa Rita, e consequentemente à leste com o Oceano Atlântico (Fig. 1). A geomorfologia e geologia de João Pessoa são caracterizados por uma cobertura sedimentar, conhecida como baixo tabuleiros costeiros que remetem a idade terciária. O solo da região é o neossolo quartzarênico e a topografia caracteriza-se por ser ser profunda, suave ondulada ou plana (BARBOSA; BARBOSA, 2016).

Localização da Área de Estudo

O cemitério São Sebastião encontra-se no bairro de Monsenhor Magno, conhecido popularmente por Muçumagro, na Rua Domingos José da Paixão, que dá acesso a PB-008 e à leste pela Praia do Sol. Encontra-se na latitude $7^{\circ} 12^{\prime} 45.49$ "S e longitude $34^{\circ} 50^{\prime} 31.55^{\prime \prime} \mathrm{W}$ e altitude de $33 \mathrm{~m}$. Foi fundado em $1951 \mathrm{com}$ uma área de $1.250 \mathrm{~m}^{2}$, o cemitério possui 206 covas perpétuas e 70 rotativas.

Localizado em uma área urbana, observa-se a presença de residências e comércio, tais como lava-jato, oficina mecânica, posto de gasolina, entre outros. $O$ cemitério é um local simples, sendo alguns túmulos identificados apenas por uma cruz e os demais por simples jazigos. Em seu interior, encontram-se uma capela e uma pequena sala de velório. Nos períodos de fortes chuvas, o terreno não é capaz de infiltrar toda a água, causando, assim, alagamentos que carregam materiais para fora do cemitério, e vice-versa.

Coleta das Amostras 
Foram realizadas oito amostragens no solo (Fig. 2), sendo quatro no lado direito do muro externo do cemitério e quatro no lado esquerdo do muro externo do cemitério, de 0,5m de profundidade com o auxílio de um trado manual.

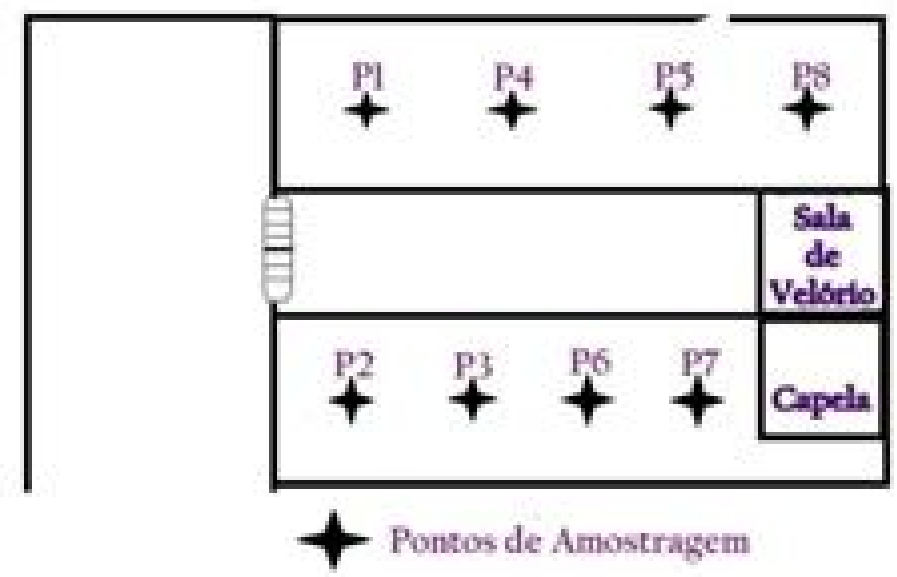

FIGURA 2 - Pontos da realização da coleta de solo. Fonte: Autores.

As amostras coletadas foram armazenadas em embalagens plásticas hermeticamente fechadas. As oito amostras foram levadas ao laboratório para secar em uma estufa com circulação de ar a $40{ }^{\circ} \mathrm{C}$ (EMBRAPA, 1997). Por sua vez, as amostras de nitrogênio também foram armazenadas em embalagens completamente lacradas e em seguidas levadas a um freezer para impedir a liberação de voláteis (EMBRAPA, 1997).

Análises Laboratoriais

As análises foram realizadas seguindo as metodologias de Embrapa (1997) e UFPB (2014). Os métodos utilizados na realização das análises foram o potenciômetro para o pH, titulação, utilizados no carbonato, bicarbonato, cloreto, acidez trocável, acidez potencial, cálcio, magnésio, matéria orgânica e nitrogênio e para sódio e potássio foi utilizado a espectrofotometria de chamas.

\section{RESULTADOS E DISCUSSÕES}

$\mathrm{pH}$

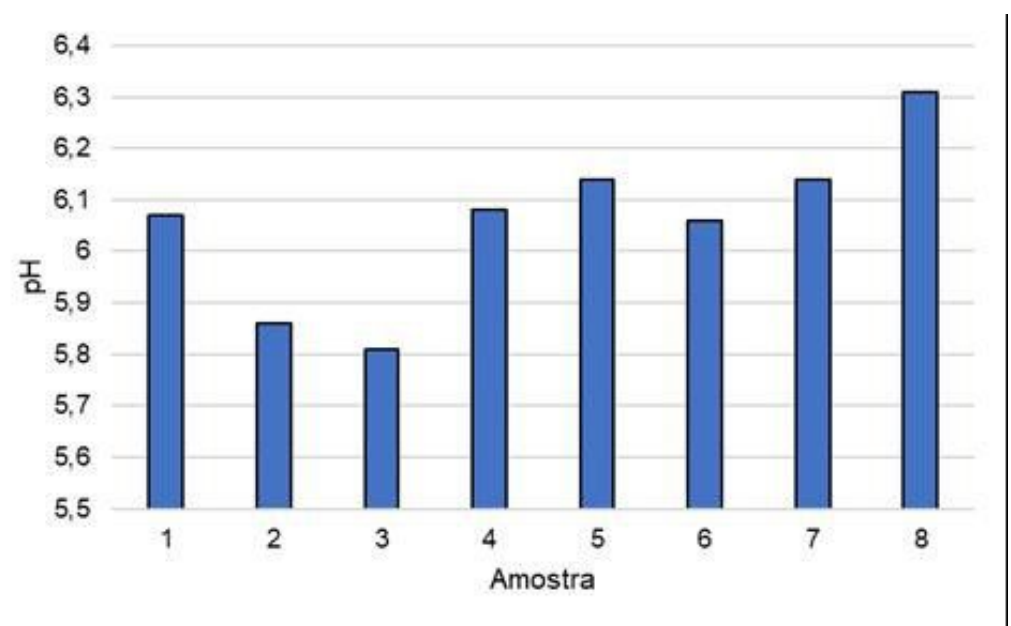

FIGURA 3 - pH dos solos nos pontos de coleta do Cemitério São Sebastião. Fonte: Autores. 
A Fig. 3 mostra o comportamento das oito amostras de solo analisadas em que se observa que maior valor de $\mathrm{pH}$ se encontra na amostra 8 , o $\mathrm{pH}$ foi de $6,31 \mathrm{e}$ o menor resultado na amostra $3, \mathrm{pH}$ de 5,81. Como os resultados das amostras foram inferiores a $\mathrm{pH} 7$, utilizando como base a escala de acidez e alcalinidade de Lopes encontrada em Brunetto et al., (2008), o pH das oito amostras ficou neutro. Essa característica pode ser favorável a vírus e bactérias, como Escherichia coli, Enterobacter, Klebsiella e Citrobacter (FUNASA, 2007).

$\mathrm{O}$ pH do solo é uma das condições para a compreensão de suas características. Baixos níveis de $\mathrm{pH}$ podem indicar a capacidade de condução de poluentes que tendem a possuir elevadas concentrações de metais (FORNASIER et al., et al., 2018; BARGRIZAN et al., 2018). Sendo um dos parâmetros mais importantes a ser considerado, o pH pode influenciar desde o desenvolvimento das plantas ao transporte de contaminantes. Além disso, não é estranho que acentuadas diferenças no $\mathrm{pH}$ sejam identificadas em pequenos intervalos (FORNASIER et al., 2018).

Carbonatos $\left(\mathrm{CO}_{3}^{2-}\right)$ e Bicarbonatos $\left(\mathrm{HCO}_{3}{ }^{-}\right)$

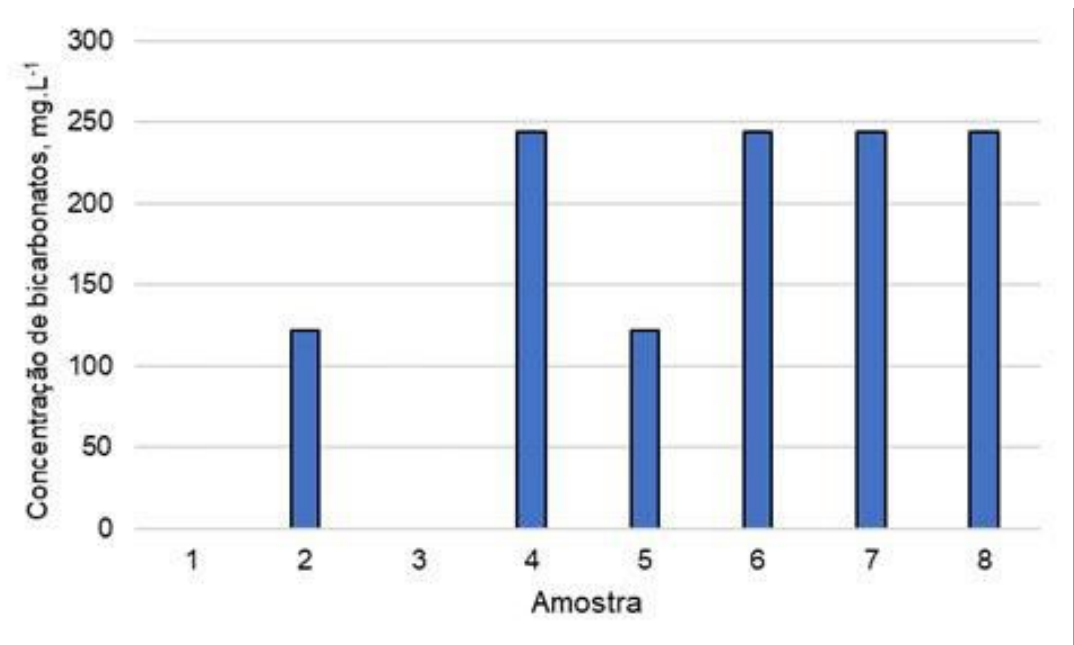

FIGURA 4 - Teor de bicarbonatos dos solos nos pontos de coleta do Cemitério São Sebastião. Fonte: Autores.

Nas oito amostras analisadas, não foi possível detectar presença de carbonato. Os valores de bicarbonato variam de 0 a $244 \mathrm{mg}^{-L^{-1}}$ (Fig. 4). As amostras 1 e 3 não indicaram presença de bicarbonato. A presença ou ausência dos carbonatos e bicarbonatos no solo está diretamente ligada à alcalinidade do mesmo (FUNASA, 2007). Este resultado ratifica o perfil ácido ou moderadamente ácido do solo do cemitério São Sebastião.

Cloretos $\left(\mathrm{Cl}^{-}\right)$ 


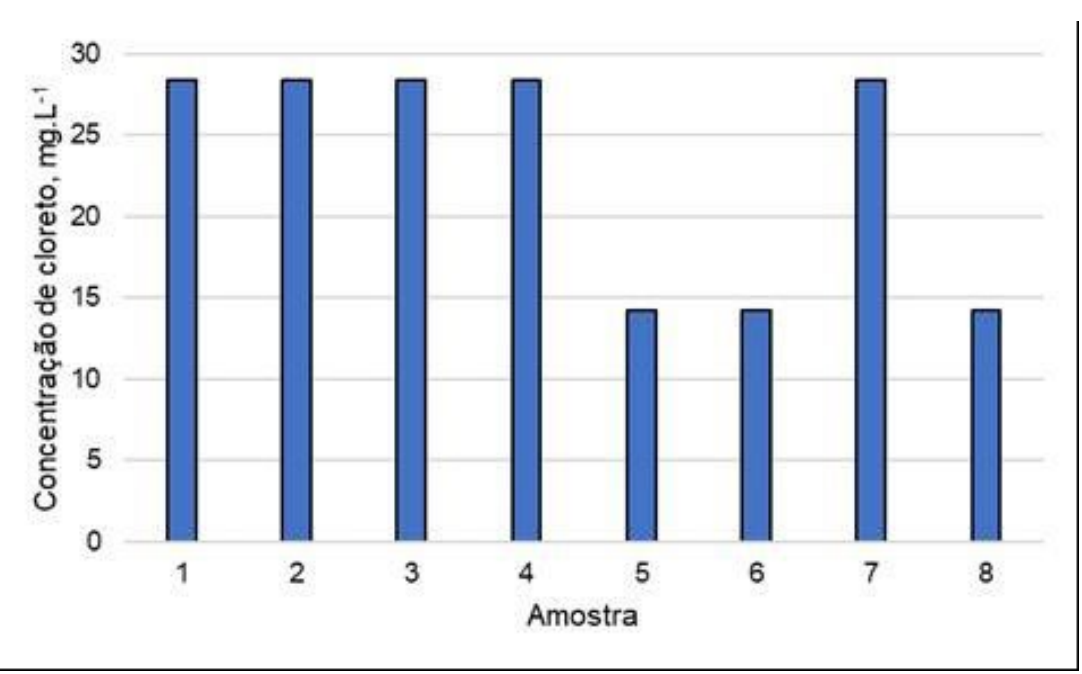

FIGURA 5 - Teor de cloreto dos solos nos pontos de coleta do Cemitério São Sebastião. Fonte: Autores.

Os valores de cloreto representados na Fig. 5 demonstram que os resultados foram de 28,36 mg. . $^{-1}$ nas amostras 1, 2, 3, 4 e 7 e as amostras 5, 6 e 8 foram de $14,18 \mathrm{mg} \cdot \mathrm{L}^{-1}$. A presença de cloreto no solo pode ocorrer por inúmeros fatores, dentre eles, a presença de contaminação resultante da ação humana, contudo, a existência de cloreto no solo não apresenta toxidade para o ser humano (GEILFUS, 2018).

Acidez Trocável $\left(\mathrm{H}^{+}+\mathrm{Al}_{3}{ }^{+}\right)$e Acidez Potencial $\left(\mathrm{H}^{+}+\mathrm{Al}_{2}{ }^{+}\right)$

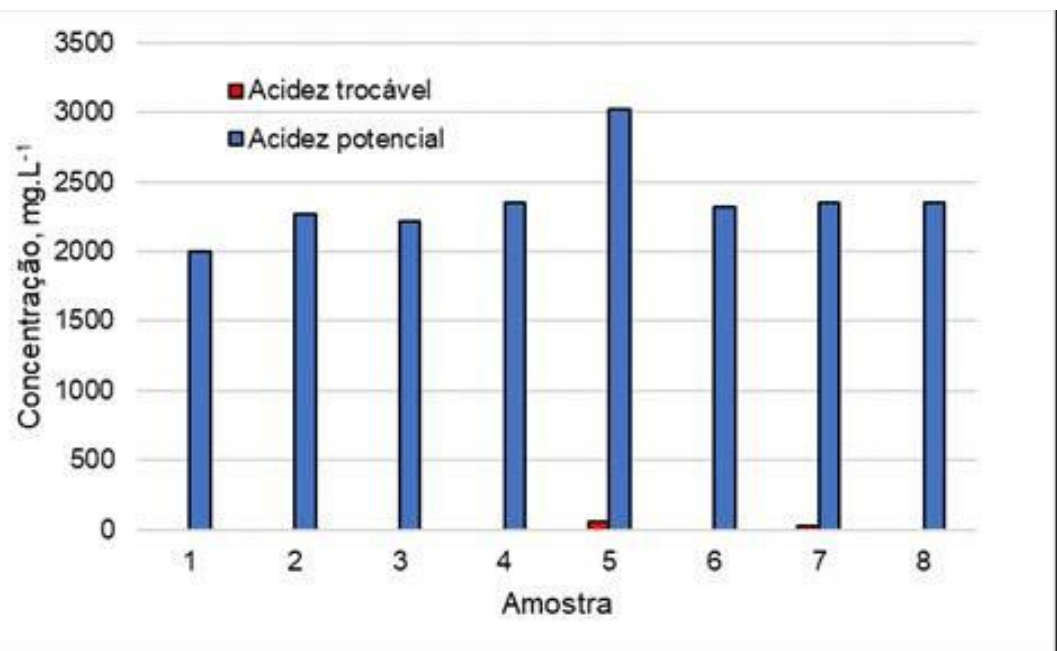

FIGURA 6 - Valores da acidez trocável e potencial dos solos nos pontos de coleta do Cemitério São Sebastião. Fonte: Autores.

Como observado na Fig. 6, foram constatados valores de acidez trocável apenas nas amostras 5, 53,96 mg. $\mathrm{L}^{-1}$ e $7,26,98 \mathrm{mg} \cdot \mathrm{L}^{-1}$. A acidez potencial apresentou valores bastante elevados que variaram de 3021,76 a 1996,52 mg.L ${ }^{-1}$. Com base em Almuktar e Scholz (2016), os níveis de alumínio estão relacionados com o pH e a matéria orgânica presente no solo. Quanto mais alumínio no solo, menor o $\mathrm{pH}$. 
A exposição humana a concentrações elevadas de alumínio pode ser um risco à saúde, promovendo desde infertilidade e aborto espontâneo até doenças coronárias (SKALNY et al., 2018). Além disso, podem estar associados a doenças neurológicas, como o mal de Alzheimer, câncer de mama, entre outras (LIU et al., 2018).

Cálcio e Magnésio $\left(\mathrm{Ca}^{2+}\right.$ e $\left.\mathrm{Mg}^{2+}\right)$

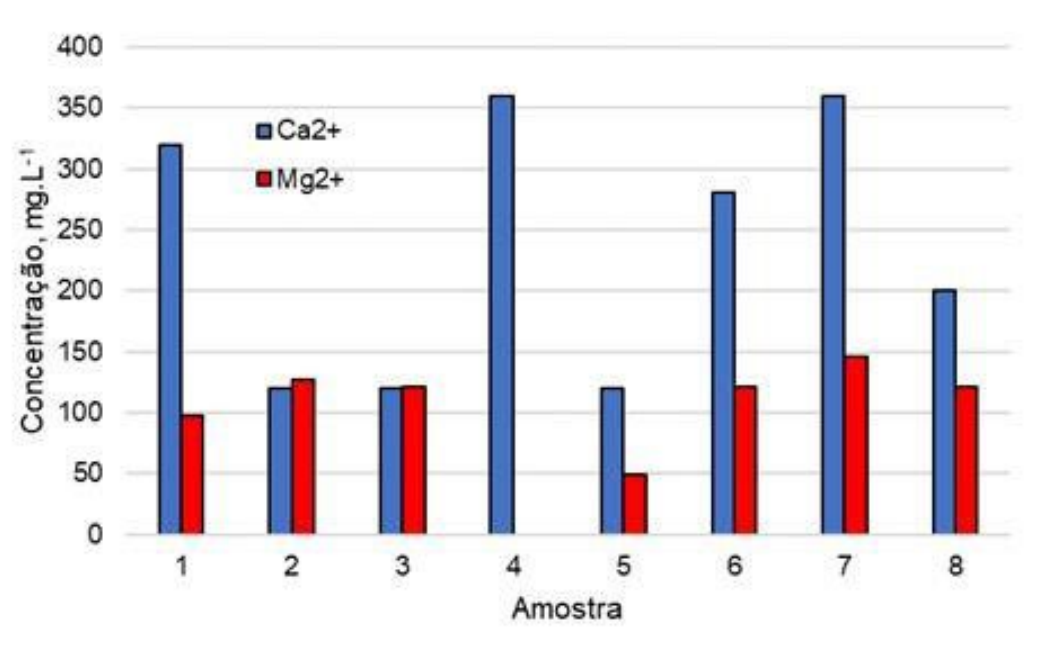

FIGURA 7 - Valores de cálcio e magnésio dos solos nos pontos de coleta do Cemitério São Sebastião. Fonte: Autores.

Como visto na Fig. 7, os maiores resultados de cálcio foram observados nas amostras 4, $360 \mathrm{mg} \cdot \mathrm{L}^{-1}$ e o menor nas amostras 2, 3 e 5, $120 \mathrm{mg} \cdot \mathrm{L}^{-1}$. Os espécimes 3,6 e 8 apresentaram o mesmo valor para magnésio, $121,55 \mathrm{mg} \cdot \mathrm{L}^{-1}$. A concentração de cálcio no solo ocorre por meio da decomposição dos ossos e dos dentes dos cadáveres (KEMERICH et al., 2013). Apesar de o cálcio e o magnésio se comportarem de forma similar no solo, as modificações que causam em sua estrutura se darão de forma diferente, como por exemplo, na adsorção do solo. $O$ magnésio pode causar alterações nas propriedades do solo e a degradação do mesmo (QADIR et al., 2018).

Potássio e Sódio $\left(\mathrm{K}^{+}\right.$e $\left.\mathrm{Na}^{+}\right)$

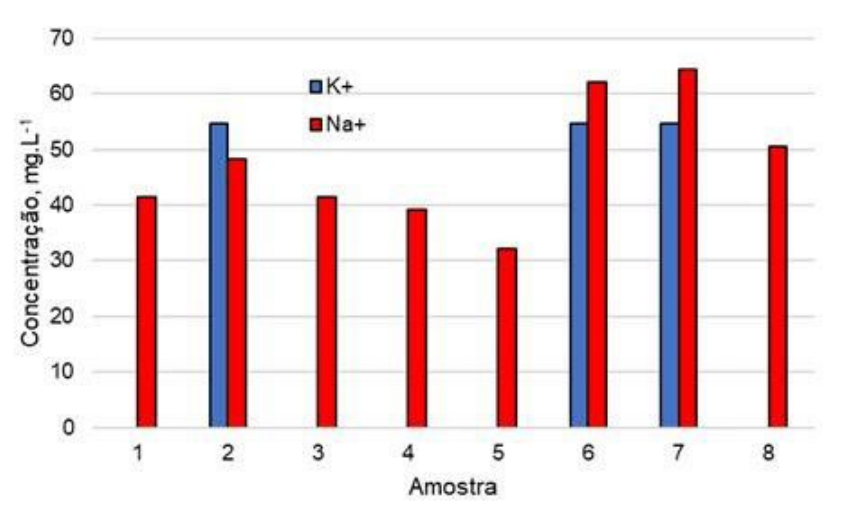

FIGURA 8 - Valores de potássio e sódio dos solos nos pontos de coleta do Cemitério São Sebastião. Fonte: Autores. 
Como observado na Fig. 8, só foi possível identificar potássio nas amostras 2 , 6 e 7 , o valor foi de $54,74 \mathrm{mg} \cdot \mathrm{L}^{-1}$. Os valores de sódio variaram de $64,37 \mathrm{mg} \cdot \mathrm{L}^{-1} \mathrm{na}$ amostra 7 e de $32,19 \mathrm{mg}^{-1} \mathrm{~L}^{-1}$, na 5 . Apesar de ser um importante elemento no desenvolvimento das plantas o potássio assim como o sódio pode causar desgaste no solo. Além disso, altas concentrações de sódio no solo podem ser prejudiciais para a vida vegetal e tóxicos para organismos vivos (MARCHUK; MARCHUK, 2018; VESSEY et al., 2018).

\section{Matéria Orgânica}

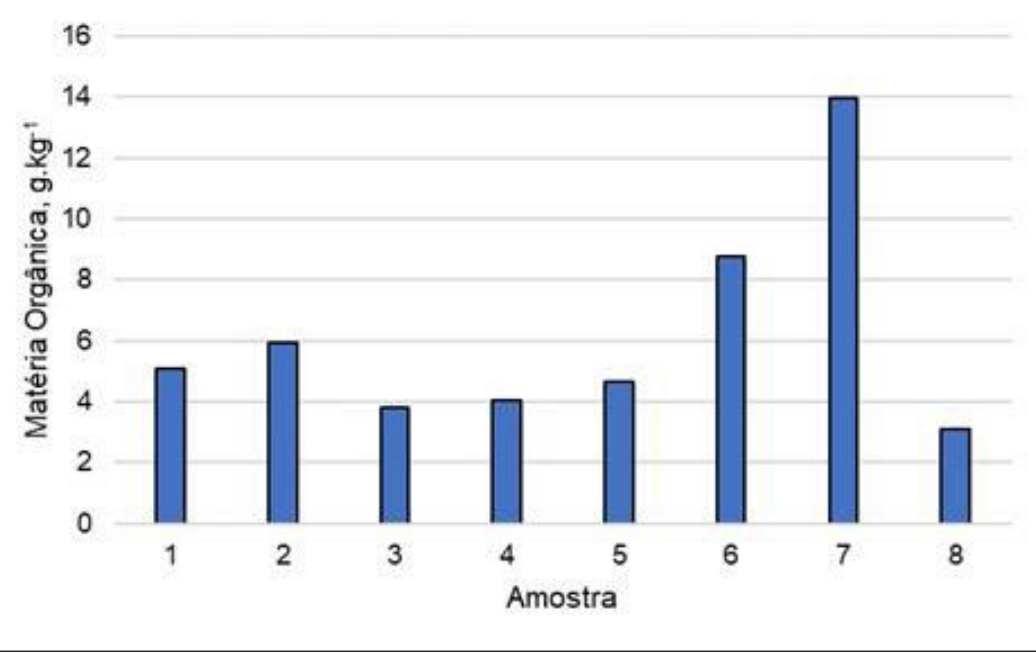

Figura 9 - Valores de matéria orgânica dos solos nos pontos de coleta do Cemitério São Sebastião. Fonte: Autores.

A Fig. 9 mostra o conteúdo orgânico de cada espécime. O maior valor de matéria orgânica na amostra 7 foi de $13,95 \mathrm{~g} \cdot \mathrm{kg}^{-1}$ e o menor valor em $3,11 \mathrm{~g} \cdot \mathrm{kg}^{-1}$, na 8. O elevado teor de água no solo afeta a temperatura. Sendo assim, solos frios são mais propensos a serem mais ricos em matéria orgânica, devido ao processo de decomposição ser mais lento. Já nos secos, os processos oxidativos degradam melhor a matéria orgânica (FUNASA, 2007). Inclusive, a quantidade de matéria orgânica encontrada no solo analisado é sobressaltante, principalmente devido ao fato de as menores quantidades de matéria orgânica serem encontradas em solos mais profundos (POLLOCK et al., 2018).

Nitrogênio 


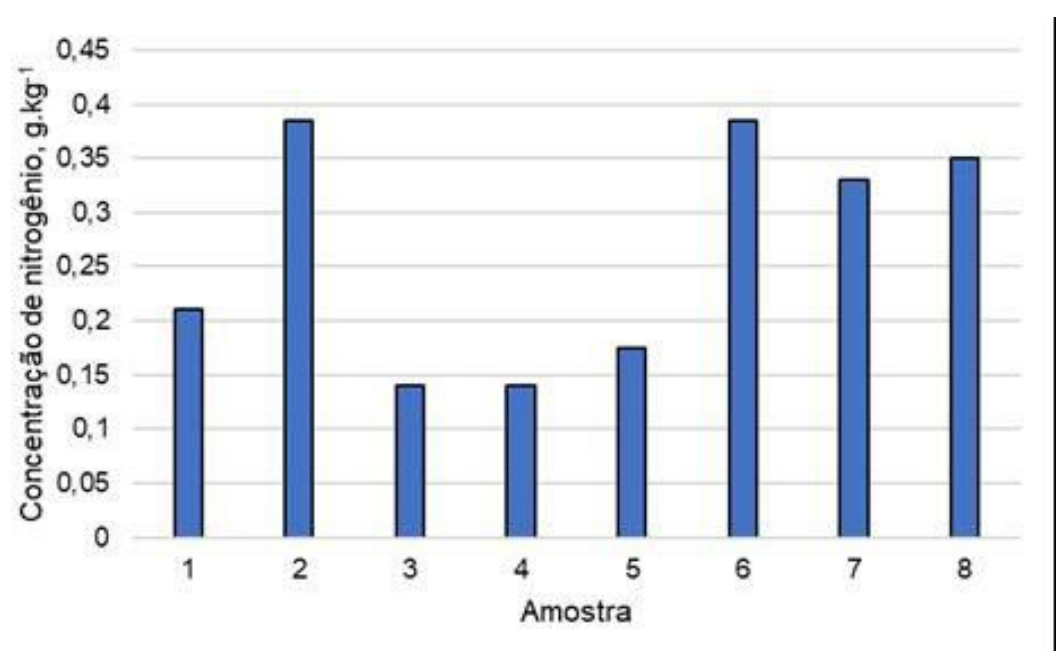

FIGURA 10 - Valores de nitrogênio dos solos nos pontos de coleta do Cemitério São Sebastião. Fonte: Autores.

Como observado na Fig. 10, os maiores valores de nitrogênio foram encontrados nas amostras 2 e 6 com $0,385 \mathrm{~g} \cdot \mathrm{kg}^{-1} \mathrm{e}$ os menores nas amostras 3 e 4 com $0,14 \mathrm{~g} \cdot \mathrm{kg}^{-1}$. Resíduos provenientes da matéria orgânica são ricos em nitrogênio e na presença de oxigênio ocorre a decomposição para nitrato. Em águas subterrâneas, o aparecimento de nitrito indica poluição recente pelo fato da oxidação para nitrato ocorrer de forma rápida (FUNASA, 2007). Quando o nitrogênio entra em contato com água, além da contaminação, este elemento pode interferir nas propriedades do solo. Sendo, assim, o nitrogênio é considerado um dos maiores contaminantes encontrados em solos cemiteriais (ZYCHOWSKI, 2012; QIAO et al, 2018).

\section{CONCLUSÃO}

Os solos analisados do Cemitério São Sebastião, em João Pessoa-PB, mostram um impacto negativo à comunidade circunvizinha devido a época de chuvas o mesmo alaga e transborda podendo carrear contaminantes como ácidos e alumínio, podendo diminuir o pH dos solos no entorno. Por estar localizado em área urbana, a administração do cemitério deveria tomar medidas para diminuir os riscos à população.

Novas coletas de solo e, consequente, suas análises físico-químicas e microbiológicas em maiores profundidades dentro do cemitério e em seu entorno, assim como entrevistas com os moradores e comerciantes devem ser realizadas para mensurar a contaminação e descrever os impactos que a atividade cemiterial pode estar causando à região.

\section{AGRADECIMENTOS}

À Dra. Maria das Graças Nóbrega de Almeida pelos oportunos e importantes comentários durante o desenvolvimento do artigo. Ao biólogo Bruno Oliveira de Veras por todo apoio na realização das análises. Ao Laboratório de Combustíveis e Materiais (LACOM/CCEN/UFPB/PB); Laboratório de Automação e Instrumentação em Química Analítica e Quimiometria (LAQA/CCEN/UFPB/PB); e Laboratório Multidisciplinar da FPB. E ao Engenheiro Ambiental Thobias Apolônio Batista da Silva pela valiosa contribuição. 


\section{REFERÊNCIAS}

ALMUKTAR, S.A.A.A.N; SCHOLZ, M. Mineral and biological contamination of soil and Capsicum annuum irrigated with recycled domestic wastewater. Revista Agricultural Water Management, v. 167, p. 95-109, 2016 Disponível em: <https://doi.org/10.1016/j.agwat.2016.01.008>. doi: 10.1016/j.agwat.2016.01.00.

BARBOSA, T. S.; BARBOSA, M. E. F. Aspectos Geomorfológicos E Mapeamento Das Unidades De Relevo Do Município De João Pessoa, Pb. Geografia Ensino \& Pesquisa, v. 20, n. 1, p. 143, 2016. Disponível em: <file:///C:/Users/ACER/Desktop/ASPECTOS_GEOMORFOLOGICOS_E_MAPEAME NTO_DAS_UNIDADES.pdf> doi:10.5902/2236499418072.

BARGRIZAN, S; SMERNIK, R.J.; FITZPATRICK, R.W.; MOSLEY, L.M.; The application of a spectrophotometric method to determine $\mathrm{pH}$ in acidic $(\mathrm{pH}<5)$ soils. Talanta, v. 186, 2018.2 Disponível em: <https://doi.org/10.1016/j.talanta.2018.04.074>. doi: 10.1016/j.talanta.2018.04.074.

BRASIL. Conselho Nacional do Meio Ambiente. Resolução no 335, de 3 de abril de 2003. Dispõe sobre o licenciamento ambiental de cemitérios. Disponível em: <http://www.mma.gov.br/port/conama/legislacao/CONAMA_RES_CONS_2003_335. pdf $>$.

BRASIL. Conselho Nacional do Meio Ambiente. Resolução no 420, de 28 de dezembro de 2009. Dispõe sobre critérios e valores orientadores de qualidade do solo quanto à presença de substâncias químicas e estabelece diretrizes para o gerenciamento ambiental de áreas contaminadas por essas substâncias em decorrência de atividades antrópicas. Disponível em: http://www.mma.gov.br/port/conama/legiabre.cfm?codlegi=620.

BENNETT. G; DAVIES P. J. Urban cemetery planning and the conflicting role of local and regional interests. Journal of Land Use Policy, v. 42, 2015. Disponível em: $<$ https://doi.org/10.1016/j.landusepol.2014.08.011>. 10.1016/j.landusepol.2014.08.011.

BRUNETTO, G.; SILVA, L. S.; CERETTA, C. A.; SANTOS, D. R. POCOJESKI, E. Acidez do solo e calagem. 2008. Disponível em: <http://w3.ufsm.br/solos/antigo/PDF/manejo\%20e\%20fertilidade\%20zootecnia/Aula \%202-Acidez\%20e\%20calagem\%20do\%20solo.pdf>.

COCKLE, D. L; BELL, L. S. The environmental variables that impact human decomposition in terrestrially exposed contexts within Canada. Science \& Justice, Volume 57, Issue 2, March 2017, Pages 107-117. Disponível em: <https://doi.org/10.1016/j.scijus.2016.11.001>. doi: 10.1016/j.scijus.2016.11.001.

EMBRAPA. Manual de Métodos de Análise de Solo. Revista e atualizada, $2^{\underline{a}}$ edição. Centro Nacional de Pesquisa de Solos. Rio de Janeiro,1997.

FORNASIER, E.; FORNASIER, F.; DI MARCO, V.; Spectrophotometric methods for the measurement of soil pH: A reappraisal. Spectrochimica Acta Part A: Molecular 
and Biomolecular Spectroscopy, v. 204, 2018. Disponível em: <https://doi.org/10.1016/j.saa.2018.06.029>. doi: 10.1016/j.saa.2018.06.029.

FUNASA. Cemitérios Como Fonte Potencial de Contaminação das Águas Subterrâneas. Região de Cuiabá e Várzea Grande (MT). Brasília, 2007. Disponível em: http://www.funasa.gov.br/site/wp-content/files_mf/cemitFonte.pdf.

GEILFUS, C. M. Chloride in soil: From nutrient to soil pollutant. Environmental and Experimental Botany, v. 157, n. October 2018, p. 299-309, 2018. Disponível em: < https://doi.org/10.1016/j.envexpbot.2018.10.035> 10.1016/j.envexpbot.2018.10.035.

KEMERICH, P. D. DA C.; SCHMACHTENBERG, N.; GRAEPIN, C.; BORBA, W. F de.; GERTHARDT, A. E et al. Potencial de contaminação do solo em cemitério na cidade de Seberi - RS. Ciência e Natura, v. 35, n. 2, p. 119-125, 2013. Disponível em: <http://dx.doi.org/10.5902/2179460X12566> doi:10.5902/2179460X12566.

LIU, Z.; HE, C.; CHEN, M.; YANG, S.; LI, J.;The effects of lead and aluminum exposure on congenital heart disease and the mechanism of oxidative stress. Reproductive Toxicology, v. 81, 2018, p. 93-98, 2018. Disponível em: <https://doi.org/10.1016/j.reprotox.2018.07.081>. doi: 10.1016/j.reprotox.2018.07.08.

MARCHUK, S.; MARCHUK, A. Effect of applied potassium concentration on clay dispersion, hydraulic conductivity, pore structure and mineralogy of two contrasting Australian soils. Soil and Tillage Research, v. 182, n. April, p. 35-44, 2018. Disponível em: <https://doi.org/10.1016/j.still.2018.04.016> doi: 10.1016/j.still.2018.04.016.

PAÍGA, P.; DELERUE-MATOS, C. Determination of pharmaceuticals in groundwater collected in five cemeteries' areas (Portugal). Science of the Total Environment, v. 1, 2016. Disponível em: <https://doi.org/10.1016/j.scitotenv.2016.06.090> doi: 10.1016/j.scitotenv.2016.06.090.

POLLOCK, C. R.; POKINES, J. T.; BETHARD, J.D. Organic staining on bone from exposure to wood and other plant materials. Forensic Science International, v. 283, 2018. Disponível em: <https://doi.org/10.1016/j.forsciint.2017.12.021>. doi: 10.1016/j.forsciint.2017.12.021.

QADIR, M.; SCHUBERT, S.; OSTER, J. D.; SPOSITO, G.; MINHAS, P.S et al. High-magnesium waters and soils: Emerging environmental and food security

constraints. Science of the Total Environment, v. 642, 2018. Disponível em: <https://doi.org/10.1016/j.scitotenv.2018.06.090> doi: 10.1016/j.scitotenv.2018.06.090. 
QIAO, J.; ZHU, Y.; JIA, X.; HUANG, L.; SHAO, M. et al. Vertical distribution of soil total nitrogen and soil total phosphorus in the critical zone on the Loess Plateau, China. CATENA, v. 166, 2018. Disponível em: <https://doi.org/10.1016/j.catena.2018.04.019>. doi: 10.1016/j.catena.2018.04.019.

RATTENBURY, A. E. Chapter 2 - Forensic Taphonomy. Forensic Ecogenomics. The Application of Microbial Ecology Analyses in Forensic Contexts 2018, p. 37-59. Disponível em: <https://doi.org/10.1016/B978-0-12-809360-3.00002-3>. doi: 10.1016/B978-0-12-809360-3.00002-3.

SANTOS, A.S. Espaços cemiteriais e suas contribuições para a paisagem e meio ambiente urbanos. Revista LabVerde, n. 6, 2013. Disponível em: $<$ https://doi.org/10.11606/issn.2179-2275.v0i6p85-105> doi: 10.11606/issn.21792275.v0i6p85-105.

SKALNY, A. V.; KAMINSKAYA, G.A.; KREKESHEVA, T.I.; ABIKENARA, S.K.; SKALNAYA, M.G et al. Assessment of hair metal levels in aluminium plant workers using scalp hair ICP-DRC-MS analysis. Journal of Trace Elements in Medicine and Biology, v. 20 2018. Disponível: <https://doi.org/10.1016/j.jtemb.2018.06.014>. doi: 10.1016/j.jtemb.2018.06.014.

SWENSEN, G. Between romantic historic landscapes, rational management models and obliterations - urban cemeteries as green memory sites. Urban Forestry \& Urban Greening, v. 33, 2018. Disponível em: <https://doi.org/10.1016/j.ufug.2018.04.013> doi: 10.1016/j.ufug.2018.04.013.

UFPB- UNIVERSIDADE FEDERAL DA PARAÍBA . Centro de Ciências Agrárias, Laboratório de Química e Fertilidade dos Solos. Metodologias para análise química da fertilidade e salinidade do solo e água. Areia, PB, 2014.

VESSEY, C. J.; LINDSAY, M. B. J.; BARBOUR, S. L. Sodium transport and attenuation in soil cover materials for oil sands mine reclamation. Applied Geochemistry, v. 100, p. 42-54, 2019. Disponível em: <https://doi.org/10.1016/j.apgeochem.2018.10.023> doi: 10.1016/j.apgeochem.2018.10.023.

YCHOWSKI, J. Impact of Cemeteries on Groundwater Chemistry: A Review. Catena v. 93, p. 29-37, 2012. Disponível em: $<$ https://doi.org/10.1016/j.catena.2012.01.009 >. doi: 10.1016/j.catena.2012.01.009.

YCHOWSKI, J e BRYNDAL, T. Impact of cemeteries on groundwater contamination by bacteria and viruses - A Review. Journal of Water e Health, v.13, n.2, p. 285301, 2015. Disponível em: < https://doi.org/10.2166/wh.2014.119>. doi: 10.2166/wh.2014.119. 